\title{
Deficits in Impulse Control Associated with Tonically-elevated Serotonergic Function in Rat Prefrontal Cortex
}

\author{
Jeffrey W. Dalley, Ph.D., David. E. Theobald, Dawn M. Eagle, Ph.D., F. Passetti, M.D.,
} and Trevor W. Robbins, Ph.D.

Converging lines of evidence suggest that dysfunction of brain serotonergic systems may underlie impulsive behavior. However, the nature of this deficit remains poorly understood because indirect indices of serotonin (5-HT) function are often used in clinical and experimental studies. In this investigation we measured 5-HT release directly in the prefrontal cortex of rats using in vivo microdialysis during performance of a visual attentional task. A number of performance measures were taken, including the number of premature responses made during the inter-trial interval before the onset of the visual discriminanda. This form of behavioral disinhibition was defined as impulsive, after Soubrié (1986). Lengthening the inter-trial interval increased the sensitivity of the task for detecting impulsive tendencies. Cortical levels of 5-HT and its metabolite 5-HIAA remained at pre-task levels over 1 h of task performance. By contrast, levels of dopamine (DA) and its metabolite DOPAC increased during this period. Regression analysis established a positive relationship between premature (impulsive) responses and 5-HT efflux, both under basal $(r=0.49)$ and task-related $(r=0.42)$ conditions $(n=31)$. No such relationship was found for prefrontal levels of DA. However, post-mortem analysis revealed that animals that were more impulsive had a higher turnover of $D A$ in anterior cingulate, prelimbic and infralimbic cortices but no detectable abnormalities in 5-HT function. These data indicate that elevated 5-HT release in the prefrontal cortex may underlie deficits in impulse control on this task. Additionally, DA dysfunction in this region may be another, possibly independent, trait marker of impulsivity.

[Neuropsychopharmacology 26:716-728, 2002] (C) 2002 American College of Neuropsychopharmacology. Published by Elsevier Science Inc.
KEY WORDS: Impulsivity; Dopamine; Serotonin; In vivo microdialysis; Attention-deficit hyperactivity disorder

There is now a substantial body of evidence implicating impaired functioning of brain serotonergic systems in

From the Department of Experimental Psychology, University of Cambridge, Downing Street, Cambridge CB2 3EB, UK.

Address correspondence to: Jeffrey W. Dalley, Ph.D., University of Cambridge Department of Experimental Psychology, Downing Street, Cambridge CB2 3EB UK, Tel.: +44 1223333 563, Fax: +44 1223333 564, E-mail: jwd20@cus.cam.ac.uk

Received June 14, 2001; revised November 6, 2001; accepted November $9,2001$.

Online publication: $11 / 12 / 01$ at www.acnp.org/citations/ Npp111201205. impulsive behavior (Linnoila et al. 1983; Harrison et al. 1997a; Puumala and Sirviö 1998; Evenden 1999b; Mobini et al. 2000). An enduring hypothesis underpinning research in this area is that reduced central serotonin (5-HT) activity, either directly or indirectly, predisposes a subject to impulsive tendencies (Linnoila et al. 1983; Wogar et al. 1993; Fairbanks et al. 2001; Mobini et al. 2000). However, the precise nature of the 5-HT impairment in impulsivity remains poorly understood because indirect indices of 5-HT function are often used in clinical and experimental studies (Linnoila et al. 1983; Fairbanks et al. 2001; Evans et al. 2000). This has been compounded by the extraordinary complexity of brain 5-HT systems with two distinct projections from the 
midbrain and at least 14 identified 5-HT receptor subtypes (Barnes and Sharp 1999). In addition, progress in this field has been hampered by the prevailing view that impulsivity is a unitary construct mediated by common abnormalities in brain 5-HT systems.

Recent studies provide support for the notion that impulsivity is a multifaceted disorder of response control (Soubrié 1986), timing (Ho et al. 1998) and/or an intolerance to delayed reinforcement (Wogar et al. 1993; Ho et al. 1998; Evenden 1999b; Rogers et al. 1999). The view that distinct neural and neurochemical systems underlie different aspects of impulsive behavior receives support from the mixed effects of 5-HT receptor ligands on different tests of impulsivity. For example, $5-\mathrm{HT}_{1 \mathrm{~A}}$ and $5-\mathrm{HT}_{2}$ receptor agonists such as $8-\mathrm{OH}-\mathrm{DPAT}$ and ( \pm )-1-(2,5-dimethoxy-4-iodophenyl)-2-aminopropane (DOI) reduce 'reflection-impulsivity' where responses need to be withheld until accurate information is available (Evenden 1999a) but increase impulsive responding in a five-choice serial reaction time (5-CSRT) task where visual targets are presented regularly but in spatially unpredictable locations (Carli and Samanin 2000; Koskinen et al. 2000a,b).

One feature of impulsive behavior that recently has received attention is the failure to inhibit responding during anticipation of visual targets in a 5-CSRT task (Harrison et al. 1997a; Koskinen et al. 2000a,b). Recently, Puumala and Sirviö (1998) evaluated whether differences in cortical monoaminergic function could account for individual variability in attentional performance and impulse control in rats tested in a 5-CSRT task. Post-mortem analysis revealed that 5-HT utilization (ratio of the 5-HT metabolite, 5-hydroxyindoleacetic acid to 5-HT) in the right frontal cortex increased proportionally with impulsive responding during the intertrial interval. These data are apparently at odds with studies where profound and global central depletion of 5-HT following lesions of the ascending 5-HTergic projections induced by the selective neurotoxin, 5,7dihydroxytryptamine, increase impulsive behavior on both a 5-CSRT task (Harrison et al. 1997a,b) and a delayof-reward choice procedure (Wogar et al. 1993; Mobini et al. 2000).

In an attempt to reconcile these findings we assessed cortical 5-HT release in vivo during performance of a simplified form of the 5-CSRT task (Carli et al. 1983) where responding for visual targets was restricted only to the central aperture of the array. This version of the task places less explicit demands on attentional resources by removing the spatial uncertainty of visual stimuli. Thus, subjects need only to predict when, rather than where, a stimulus will occur. A critical element of the task is the capacity to inhibit premature responding during the inter-trial interval of $5 \mathrm{~s}$ prior to the presentation of the visual discriminanda. Following Soubrié (1986) we defined this form of behavior as impulsive, although it is recognized that this term potentially encompasses a much wider repertoire of behavioral control processes (see Evenden 1999b). In order to increase the sensitivity of the procedure to detect impulsive tendencies, subjects were challenged with sessions incorporating a longer inter-trial interval of $7 \mathrm{~s}$. In view of the mutual antagonism between 5-HT and dopamine (DA) systems, particularly in the frontal cortex (Millan et al. 1998) and the ameliorative effects of psychomotor stimulants in attention-deficit hyperactivity disorder (ADHD) (Morrow 1991) we also measured DA in the dialysate fluid. In addition, we assessed the hypothesis that an asymmetry in 5-HT function, particularly in the frontal cortex, may underlie poor impulse control (Puumala and Sirviö 1998) by determining tissue concentrations of 5-HT and DA in several regions of the cerebral cortex and striatum. Indices of 5-HT and DA utilization were inferred by the ratio of the respective metabolites, 5-hydroxy-indole-acetic acid (5-HIAA) and 3,4-dihydroxy-phenyl-acetic acid (DOPAC) to parent transmitter.

\section{METHOD}

\section{Subjects}

The subjects were 40 male Lister-Hooded rats (Harlan Olac, Bicester, U.K.) weighing 280-320 g prior to training. Nine subjects were withdrawn from the study for technical reasons relating to the in vivo microdialysis procedure $(n=6)$ or for failing to maintain a stable level of performance on the task $(n=3)$. Subjects were housed in pairs until surgery and then alone under temperature-controlled conditions $\left(21-23^{\circ} \mathrm{C}\right)$ and an alternating $12 \mathrm{~h}$ light/dark cycle (lights off from 7:30 A.M. until 7:30 P.M.). Rats received water ad libitum and $16 \mathrm{~g}$ of laboratory chow once daily. On days where animals were not run food intake was increased to $20 \mathrm{~g} / \mathrm{sub}-$ ject/day. All experiments were conducted in strict accordance with the U.K. Animals (Scientific Procedures) Act of 1986.

\section{Apparatus}

The apparatus consisted of eight $25 \times 25 \times 25$-cm ninehole boxes (Carli et al. 1983), each placed inside a ventilated sound attenuating chamber and illuminated by a $3 \mathrm{~W}$ white house light that was located centrally on a Perspex ceiling. Each operant box consisted of a curved rear wall made of aluminum, into which was set nine evenly spaced $2.5-\mathrm{cm}$ square holes, $4 \mathrm{~cm}$ deep and $2 \mathrm{~cm}$ above a wire grid floor. Each hole had an infrared beam that monitored the entrance vertically for a nose-poke response. A $3 \mathrm{~W}$ white light at the rear of each hole, which was $1 \mathrm{~cm}$ in diameter, provided the illumination for that hole. Metal caps blocked all holes, except the center hole. Food pellets (Noyes dustless pellets $45 \mathrm{mg}$; 
Sandown Scientific UK) were dispensed to a magazine at the front of the box. A hinged panel blocked the entrance to the magazine. The distance from the center hole at the rear of the box and the magazine panel was $25 \mathrm{~cm}$. Each apparatus was controlled by software written in BBC BASIC (Paul Fray Ltd, Cambridge, UK) running on an Acorn Archimedes series computer.

\section{Training}

Animals were trained to respond to brief flashes of light presently in the center hole. This was achieved over approximately 48-64 sessions (six sessions a week), each session consisting of 100 trials lasting approximately 30 $\mathrm{min}$. Initially, animals were habituated to the apparatus over two consecutive days (20-min sessions) with 5-10 pellets placed in the center hole and magazine. The illumination of the house-light and the delivery of a single pellet thereafter signaled the start of each session. Opening the panel to collect the pellet began the first trial. After a fixed delay of $5 \mathrm{~s}$ (the inter-trial interval, (ITI)), a light at the rear of the center hole was illuminated for a short period. Nose-poke responses in the center hole while the light was on or for a 5-s period afterwards (the limited hold) were deemed 'correct responses' and were rewarded by the delivery of a single pellet in the magazine. A failure to respond within the limited hold period ('omission') was punished by the house light being extinguished for $5 \mathrm{~s}$ (time-out period). Responses made in the center hole prior to the onset of the light stimulus ('premature response') were punished by a 5 -s time-out period.

In the first session of training the stimulus duration and limited hold were each $30 \mathrm{~s}$ in length. Thereafter, depending on the subjects' individual performances, these were progressively reduced to 0.5 and $5 \mathrm{~s}$, respectively. The ITI was set at $2 \mathrm{~s}$ during early training sessions when the stimulus duration was greater than or equal to $20 \mathrm{~s}$ in order to increase the number of trials for each session. Subjects were considered to have acquired the task and be eligible for surgery when $80 \%$ of trials were correct responses and fewer than $20 \%$ of trials were omissions. Prior to surgery, animals were behaviorally challenged with one session consisting of an initial 15-min baseline period (ITI = 5 s), a 15 min challenge period (ITI $=7 \mathrm{~s}$ ) and a 15-min recovery period where the ITI was returned to $5 \mathrm{~s}$. The same procedure was repeated prior to the implantation of the dialysis probe and again during the microdialysis experiment.

\section{Surgical Procedures}

Animals were anesthetized with ketamine (Ketalar, Vet Drug, U.K., $90 \mathrm{mg} / \mathrm{kg}$ i.p.) and xylazine (Rompun Vet Drug, U.K., $6.7 \mathrm{mg} / \mathrm{kg}$ i.p.) and secured in a stereotaxic frame in a 'flat-skull' position. A mid-line incision was made and the skin retracted to reveal bregma and lambda. A small plastic tethering post (diameter $\times$ length, $4 \mathrm{~mm} \times 10 \mathrm{~mm}$ ) was secured on the skull near to lambda using four bone screws and dental cement. After surgery, rats were housed individually and allowed 5 days to recover before being habituated to the counterbalanced tethering apparatus. This consisted of 5 consecutive daily sessions of 100 trials on the basic task (ITI $=5 \mathrm{~s}$ ) with the spring tether connected to the subject. The tether was connected to the subject by a small clamp on the skull post and was fed vertically to a counterbalanced arm that was located centrally on the upper surface of the sound attenuating chamber. Once asymptotic performance had been re-established subjects were challenged with a fixed long ITI of $7 \mathrm{~s}$ using an ABA design, as described above. Two days later a concentric-design microdialysis probe was implanted in the medial prefrontal cortex under ketamine and $x y-$ lazine anesthesia. The dialysis probes were made using 2-mm lengths of AN69 membrane (Fitral 16; Hospal, UK, see Dalley et al. (1998) for construction details) and implanted at $12^{\circ}$ to the perpendicular using standard stereotaxic techniques (Paxinos and Watson 1986). The coordinates used were anteroposterior $(+3.0 \mathrm{~mm}$ forward to bregma), lateral ( $\pm 1.2 \mathrm{~mm}$ from the midline), dorsolateral $(-4.0 \mathrm{~mm}$ from the dural surface). The probe was filled with artificial cerebrospinal fluid (aCSF, see below for composition details) and secured on the skull, adjacent to the plastic tethering post, using two bone screws and dental cement. Rats were allowed $48 \mathrm{~h}$ to recover before the microdialysis experiment.

\section{In vivo Microdialysis}

Experiments commenced at approximately the same time each day (1-2 P.M.). The spring tether and primed perfusion lines were connected to the skull post and dialysis probe, respectively, and the subject was placed in the 9-hole box. The aCSF perfusate $(\mathrm{NaCl} 147 \mathrm{mM}, \mathrm{KCl}$ $3 \mathrm{mM}, \mathrm{MgCl}_{2} 1.0 \mathrm{mM}, \mathrm{CaCl}_{2} 1.3 \mathrm{mM}, \mathrm{Na}_{2} \mathrm{HPO}_{4} 1.3 \mathrm{mM}$, $\mathrm{NaH}_{2} \mathrm{PO}_{4} \cdot 2 \mathrm{H}_{2} \mathrm{O} 0.2 \mathrm{mM}, \mathrm{pH} 7.4$ ) was pumped at $2 \mu \mathrm{l} /$ min through tubing $(0.28 \mathrm{~mm}$ i.d., 0.61 o.d., Portex Ltd, Hythe, U.K.) which connected in series a dual channel liquid swivel (Instech, Stoelting, USA) with the dialysis probe. The perfusate also contained a low concentration of citalopram $(1 \mu \mathrm{M})$ to augment levels of $5-\mathrm{HT}$ in the dialysate fluid. The outlet tubing (FEP tubing, $1.2 \mu \mathrm{l} /$ $100 \mathrm{~mm}$, Biotech Instruments Ltd., U.K.) was passed inside the spring tether to emerge below the rotational plane of the liquid swivel. Six 10-min basal samples were collected $1 \mathrm{~h}$ after probe connection. A further six 10-min samples were collected during task performance. Samples were stored on dry ice and then at $80^{\circ} \mathrm{C}$ before being analyzed for DA and 5-HT content. A preliminary experiment established that basal levels of 5-HT were reduced to levels below the limit of analyti- 
cal detection by the inclusion of $2 \mu \mathrm{M}$ tetrodotoxin citrate (Tocris Ltd., U.K) in the perfusate. This validation experiment confirmed that basal 5-HT efflux depends highly on physiological serotonergic neurotransmission in the medial prefrontal cortex.

\section{Ex vivo Neurochemistry}

Approximately three days after the microdialysis experiment, animals were sacrificed by $\mathrm{CO}_{2}$-induced asphyxiation. Their brains were removed and a single transverse cut was made to remove the cerebellum and brain stem. The flat surface of the remaining section of brain was then mounted with Tissue Tek onto a pre-chilled aluminum disk and stored at $-80^{\circ} \mathrm{C}$ for approximately two weeks. Brains were then sectioned on a Cryostat into $150-\mu \mathrm{m}$ coronal sections with every third section from the frontal pole being mounted onto pre-chilled microscope slides. Sections containing track damage were separately mounted for later verification of the probe position in the prefrontal cortex. As shown in Figure 1, aliquots of tissue were removed from four consecutive sections using a micropunch of diameter $0.75 \mathrm{~mm}$ (further details of this procedure can be (a)

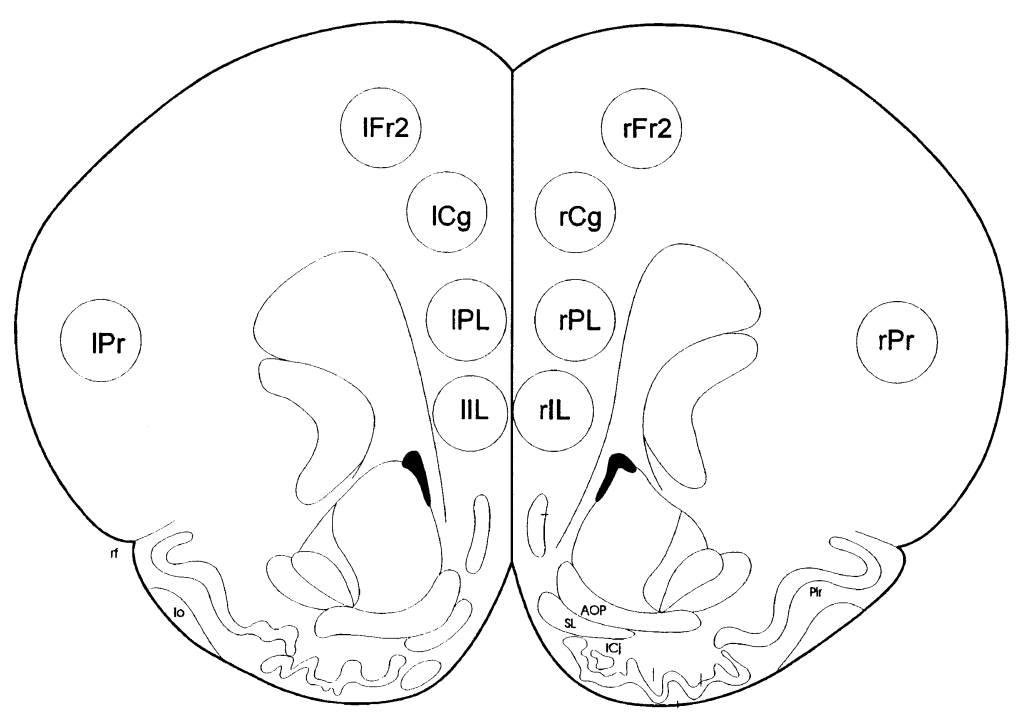

$1.90-2.50 \mathrm{~mm}$
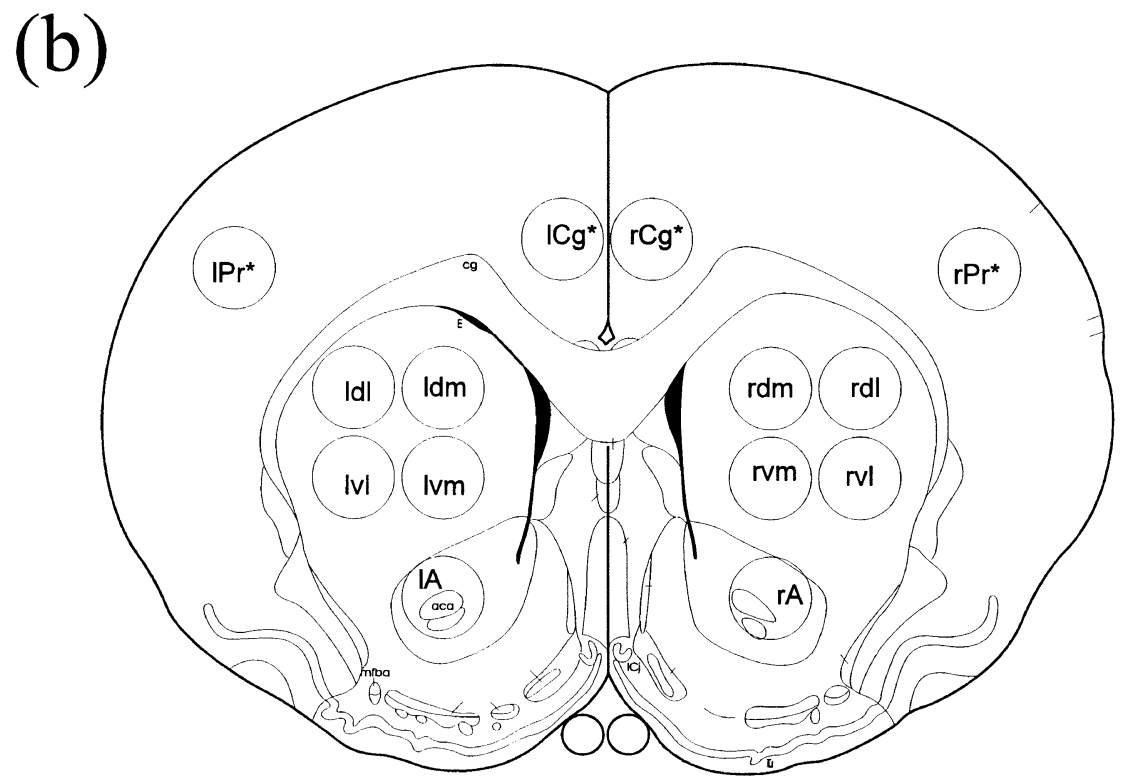

Figure 1. Schematic diagrams showing the position of micro-punched tissue aliquots from (a) pre-genual and (b) postgenual coronal sections of the rat forebrain. Tissue extracts were taken from left (l) and right ( $r$ ) cerebral hemispheres from four consecutive $150-\mu \mathrm{m}$ sections. The numbers below each section refer to stereotaxic coordinates forward to bregma (adapted from Paxinos and Watson 1986). IL (infralimbic cortex), PL (prelimbic cortex), Cg* (cingulate cortex), Fr2 (supplementary motor cortex), $\operatorname{Pr}^{*}$ (parietal cortex), A (nucleus accumbens), vm (ventromedial striatum), vl (ventrolateral striatum), dm (dorsomedial striatum), dl (dorsolateral striatum). ${ }^{*}$ Denotes post-genual region. 
found in Palkovits 1973). Samples were homogenized in $60 \mu \mathrm{l}$ of $0.2 \mathrm{M}$ perchloric acid, spun at $6000 \mathrm{rpm}$ for 20 $\min \left(4^{\circ} \mathrm{C}\right)$ and analyzed for DA and 5-HT content.

\section{In vivo and ex vivo Neurochemical Analysis}

DA and 5-HT were determined in microdialysate fluid by reversed phase high-performance liquid chromatography (HPLC) with electrochemical detection. In each case $15 \mu$ l of sample was automatically injected (Gilson 234 autoinjector, Anachem Ltd., UK) onto a C18 ODS $5 \mu \mathrm{m}$ analytical column $(100 \mathrm{~mm}$ length $\times 4.6 \mathrm{~mm}$ i.d., Hypersil Elite, Phenomenex, U.K.) with a mobile phase consisting of $\mathrm{KH}_{2} \mathrm{PO}_{4}(13.6 \mathrm{~g} / \mathrm{L})$, octane sulphonic acid $(185 \mathrm{mg} / \mathrm{L})$ and methanol $18 \%(\mathrm{pH} 2.75)$ delivered at 1 $\mathrm{ml} / \mathrm{min}$. DA and 5-HT were quantified using an ESA Coulochem II detector and an analytical cell (ESA model 5014) with two electrodes in series. The potential of the first (reducing) electrode was held at $-250 \mathrm{mV}$ (100 nA) while the potential of the second (oxidizing) electrode was set to $+250 \mathrm{mV}(10 \mathrm{nA})$ relative to a platinum reference electrode. The resultant signal from E2 was integrated using Gyncosoft software (version 5.50).

DA and 5-HT were determined in tissue aliquots using HPLC with electrochemical detection (see Matthews et al. 2001). Briefly, a citric acid-sodium acetate buffer $(\mathrm{pH}$ 3.6) was used to resolve compounds of interest on a C18 analytical column $(150 \times 4.6 \mathrm{~mm}$, Hypersil, Hichrom, U.K.) at $30^{\circ} \mathrm{C}$. Quantification was achieved using a Coulochem II detector with an analytical cell (ESA model 5014B) and two electrodes in series (E1 -250 mV, E2 + $250 \mathrm{mV}$ ). The signal from E2 was integrated using computer software (Gyncosoft version 5.50).

\section{Data Analyses}

Statistical analyses were conducted using SPSS for Windows (release 9.0, SPSS Inc., Chicago, IL, USA) or GBSTAT (Dynamic Microsystems Inc., USA). Initial behavioral analysis evaluated the frequency distribution of premature responding over a 1-h session. GraphPad Prism (version 2.01, GraphPad Software Inc., CA, USA) was used to assess the goodness-of-fit of a Gaussian distribution. The subsequent division of subjects into low $(\mathrm{n}=24)$ and high $(\mathrm{n}=7)$ impulsive responders (less than or greater than $20 \%$, respectively) was maintained throughout the remaining analyses. Three-way repeated measures analysis of variance (ANOVA) was used to compare the number of premature responses, trials and omissions over the 1-h session with one between-subjects factor, Group (2 levels; low, high) and two repeated within-subjects factors, ITI (three levels: $5 \mathrm{~s}, 7 \mathrm{~s}, 5 \mathrm{~s}$ ) and block (2 levels: 0-10 min, 10-20 min). Violations of sphericity were corrected using the Huynh-Feldt epsilon to adjust the degrees of freedom for each test. Dialysis data (fmoles/10-min sample) were analyzed by two-way ANOVA with factors, group (2 levels; low and high) and performance (2 levels; basal and task). Linear regression (Pearson's r) was used to assess the relationship between basal and task-related levels of 5-HT and DA and (\%) premature responses on-task. Ex vivo measures of 5-HT and DA function were compared by ANOVA on logarithmic transformed data $[\log 10(n+1)]$ with factors, region (12 levels) and group (two levels). Pair-wise comparisons were conducted using modified Bonferroni $t$-tests to control the family-wise $\alpha$ level.

\section{RESULTS}

\section{Behavioral Assessment}

Figure 2 shows the sequence of procedures used in the study. Subjects were divided into two groups based on their tendency to make premature responses over a 60min session where the ITI was varied systemically between 5 and $7 \mathrm{~s}$ (see Figure 3). A bimodal Gaussian distribution best modeled the data with the majority of subjects $(n=24,77.4 \%)$ making 10.4 percent of trials prematurely while the remaining subjects $(n=7,22.6 \%)$ made 24.3 percent of trials prematurely. Based on this distribution the criteria for assigning rats to low and high impulsivity groups was set by the proportion of premature responses being less than, or greater than $20 \%$, respectively of completed trials.

The temporal profile of behavioral performance variables, measured in conjunction with in vivo microdialysis, is shown in Figure 4. Subjects in the high response group made more premature responses over the 60-min session (group: $\mathrm{F}_{1,29}=66.1 ; p<.01$ ) irrespective of block or ITI (group X block X ITI: $\mathrm{F}_{2,58}=0.39 ; \epsilon=0.92 ; p=$ .68). Increasing the length of the ITI significantly increased premature responding (ITI: $\mathrm{F}_{2,58}=155.8 ; \epsilon=$ $0.71 ; p<.01$ ), particularly in the high response group. However, relative to the preceding block (sample 2) this increase was similar for both groups $(p=.11)$. Subjects were equally engaged on the task with a comparable number of trials completed (group: $\mathrm{F}_{1,29}=1.35 ; p=$ .255 ) over ITI (group X ITI: $\mathrm{F}_{2,58}=0.51 ; \epsilon=0.93 ; p=.59$ ) and block (group $\mathrm{X}$ block: $\mathrm{F}_{1,29}=1.14 ; p=.30$ ). Trial density decreased during the 7-s ITI period (ITI: $\mathrm{F}_{2,58}=$ $11.74 ; \epsilon=0.93 ; p<.01)$ in response to the restricted opportunity available in which to initiate trials. Omissions remained low and relatively stable over the 60 -min session (ITI: $\mathrm{F}_{2,58}=1.64 ; \epsilon=0.91 ; p=.21$; block: $\mathrm{F}_{1,28}=2.42$; $p=.13)$, with no group differences $\left(\mathrm{F}_{1,29}=0.66 ; p=.43\right)$.

\section{In vivo Neurochemistry}

Post-mortem examination revealed that microdialysis probes were all located within the prelimbic region of 
Training to criterion ( $>80 \%$ correct trials $<20 \%$ omissions) over $48-64$ sessions

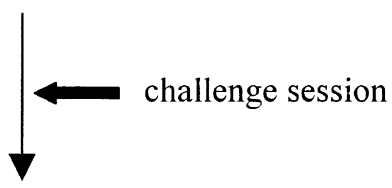

Surgery (I): Placement of a plastic tethering post on the skull

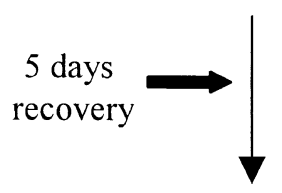

Habituation to the counterbalanced spring tether over 5 sessions

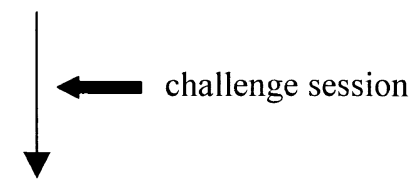

Surgery (II): Implantation of a microdialysis probe in the medial prefrontal cortex

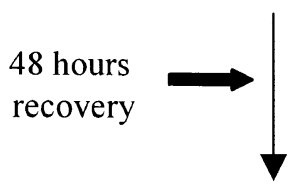

In-vivo microdialysis

1 hour equilibration; 1 hour basal

collection; 1 hour task performance

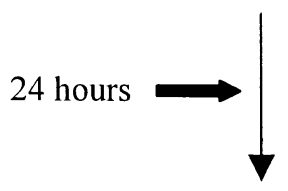

\section{Post-mortem analysis of 5-HT and \\ DA in 12 forebrain regions}

Figure 2. Flow chart showing the sequence of experimental procedures used in the study. The experiment was conducted over approximately 14 weeks with an initial cohort of 40 subjects. Nine subjects were excluded from the study for not achieving stable criterion performance or for technical reasons relating to the in vivo microdialysis procedure. The challenge sessions consisted of a 15-min baseline period $($ ITI $=5 \mathrm{~s})$, a 15-min period with a longer fixed ITI of $7 \mathrm{~s}$ and a 15-min phase where the ITI was returned to $5 \mathrm{~s}$.

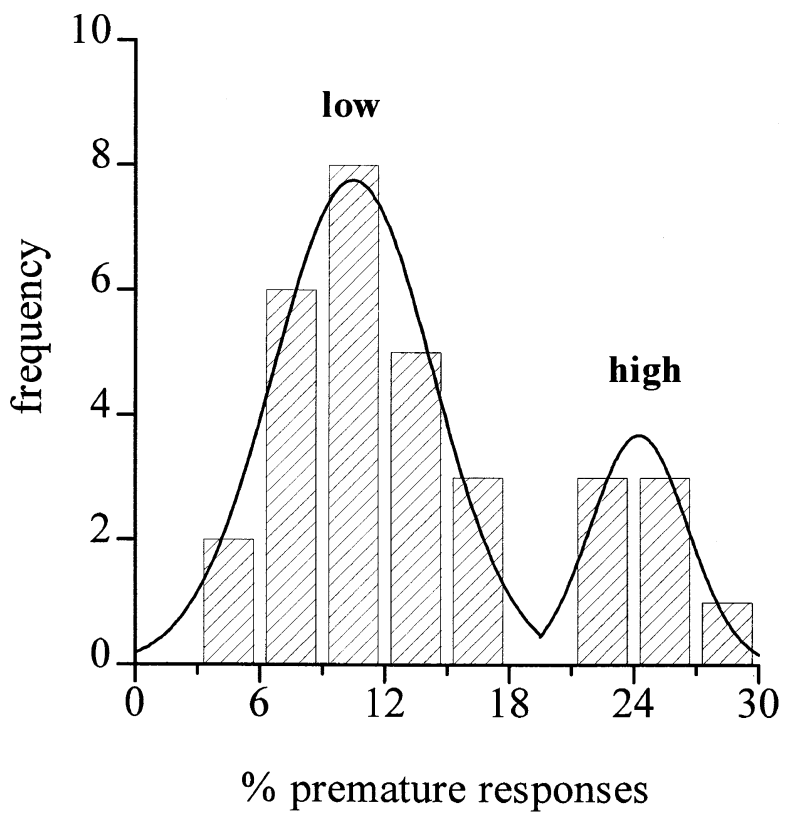

Figure 3. Frequency distribution of premature responses over a 1-h test session, as assessed concurrently with in vivo microdialysis. The ITI was set at $5 \mathrm{~s}$ for the first $20 \mathrm{~min}, 7 \mathrm{~s}$ for the next $20 \mathrm{~min}$ and $5 \mathrm{~s}$ for the final $20 \mathrm{~min}$ (see Figure 4). The abscissa scale was divided into 10 bins, each spanning 3 percentage units. It can be seen that the data are best modeled by a two-component Gaussian function $\left(\mathrm{R}^{2}\right.$ low $=$ $0.9699, R^{2}$ high $\left.=0.9576\right)$. The mean ( \pm S.E.M.) of the first component ('low' impulsives) was determined to be $10.44 \pm$ $0.76(n=24)$ while the mean of the second component ('high' impulsives) was $24.26 \pm 0.88(n=7)$. Henceforth, highly impulsive subjects are defined as those who make more than $20 \%$ premature responses over the course of a $1-\mathrm{h}$ challenge session.

the prefrontal cortex, approximately 3.0 to $3.5 \mathrm{~mm}$ forward to bregma (Paxinos and Watson 1986). A representative photomicrograph of a probe track in the prefrontal cortex is shown in a recently published study (Passetti et al. 2000).

The effects of task performance on 5-HT and DA levels, and their respective metabolites 5-HIAA and DOPAC, in the prefrontal cortex of low and high impulsive subjects are shown in Figure 5. Basal levels of 5-HT (fmoles/ 10 -min \pm S.E.M.) for low $(n=24)$ and high $(n=7)$ groups were $33.7 \pm 2.7$ and $42.4 \pm 6.5$, respectively. Basal levels of DA (fmoles/10-min \pm S.E.M.) for low $(n=17)$ and high $(n=4)$ subjects were $1.61 \pm 0.56$ and $1.18 \pm$ 0.45 , respectively. The fewer number of subjects contributing to the DA data set was due to an inability to reliably detect basal DA efflux in ten subjects. However, this is unlikely to affect the overall conclusions of the study since the proportion of subjects lost in this way was approximately the same for both groups. Basal 5HIAA and DOPAC levels (pmoles/10 $\mathrm{min} \pm$ S.E.M.) 


\section{Premature responses}
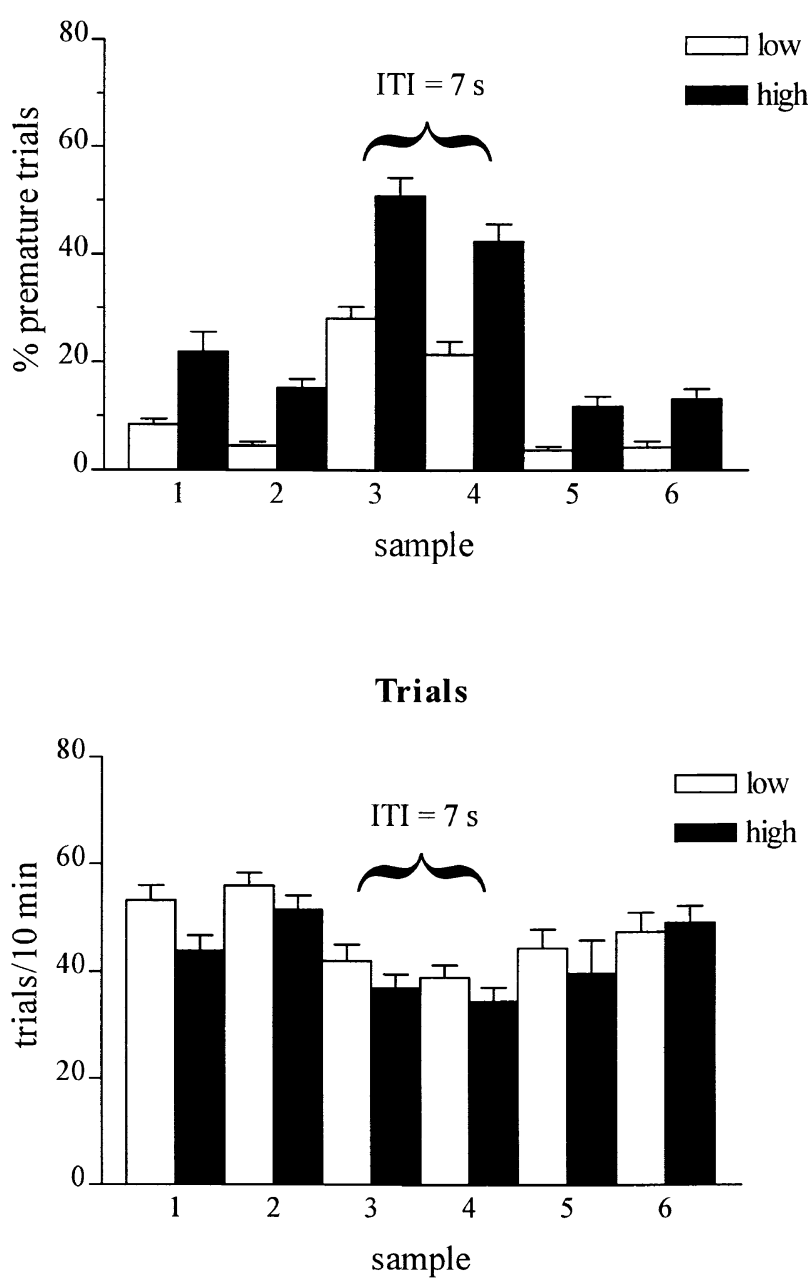

Omissions

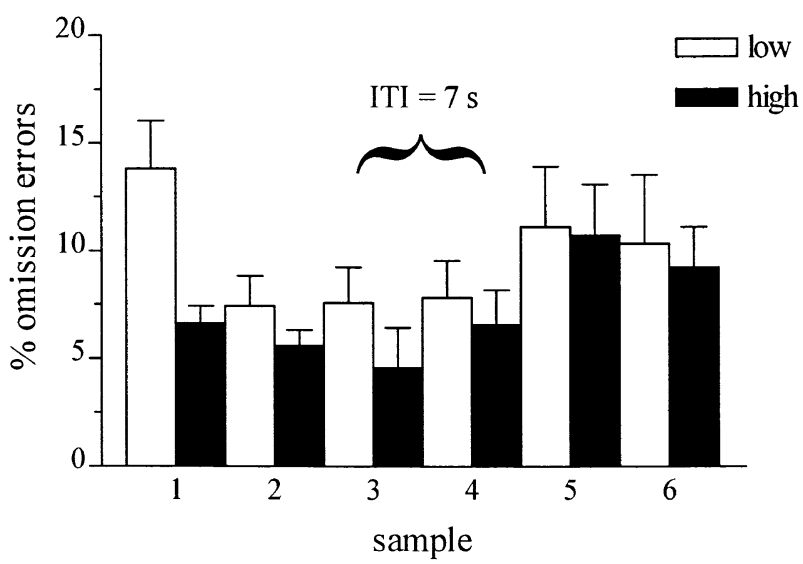

Figure 4. Bar charts showing the temporal profile of premature responses, total trials and omissions over a 1-h session, as assessed simultaneously with in vivo microdialysis. The ITI was set at $5 \mathrm{~s}$ for the first $20 \mathrm{~min}$ (samples 1 and 2), $7 \mathrm{~s}$ for the next $20 \mathrm{~min}$ (samples 3 and 4 ) and $5 \mathrm{~s}$ for the final 20
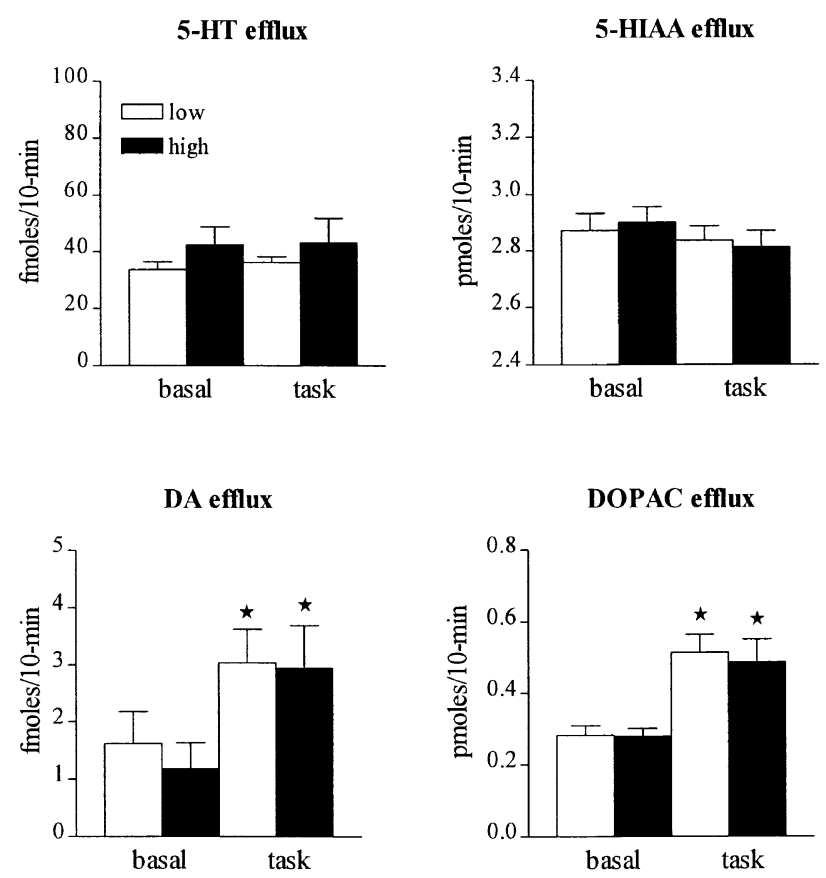

Figure 5. Effect of task performance on levels of 5-HT, 5-HIAA, DA and DOPAC in cortical dialysate samples. The task was initiated following the collection of six 10-min basal samples. Basal efflux (fmoles \pm S.E.M.) for low $(n=24)$ and high $(n=7)$ impulsive subjects was determined over the final three samples prior to task onset. Task-related levels were averaged over six consecutive 10-min samples. Due to technical difficulties the n-value for the analysis of DA was restricted to 21 subjects. Of these, four subjects were deemed to be highly impulsive while the remaining seventeen subjects were low responders. ${ }^{*} p<.05$ (basal versus task levels).

were $2.87 \pm 0.06$ and $0.282 \pm 0.027$ for low responders and $2.90 \pm 0.06$ and $0.279 \pm 0.023$ for high responders, respectively. These levels compare well with published reports (Ahn and Philips 1999; Gronier et al. 2000).

Basal levels of 5-HT, DA, DOPAC and 5-HIAA were not significantly different between low and high impulsive subjects (all $\mathrm{F}<1$ ). Extracellular levels of 5-HT and 5-HIAA did not change during performance on the task (5-HT performance: $\mathrm{F}_{1,29}=0.82 ; p=.37,5$-HIAA performance: $\left.\mathrm{F}_{1,29}=3.48 ; p=.072\right)$. Furthermore, there was no significant main effect of group (5-HT group: $\mathrm{F}_{1,29}=1.81$; $p=.19,5$-HIAA: $\left.\mathrm{F}_{1,29}=0.01 ; p=.97\right)$ and no group $\mathrm{X}$ performance interactions (all $\mathrm{F}<1$ ). In contrast, DA

min (samples 5 and 6). The data are percentage premature responses or omissions (relative to the total number of trials) averaged over 10-min bins ( \pm S.E.M.). The subjects were divided into two groups (high and low) on the basis of their tendency to make premature responses (see Figure 3). 
and DOPAC efflux increased significantly during performance (DA performance: $\mathrm{F}_{1,19}=21.4 ; p<.01$, DOPAC performance: $\mathrm{F}_{1,28}=61.5 ; p<.01$ ), each by approximately $100 \%$ compared with pre-task levels. There was no significant main effect of group (DA group: $\mathrm{F}_{1,19}=0.14$; $p=.71$, DOPAC group: $\left.\mathrm{F}_{1,28}=0.04 ; p=.84\right)$ and no group by performance interactions (all $\mathrm{F}<1$ ). Therefore, performance on the task was associated with a significant and specific increase in DA function in the prefrontal cortex. Subjects exhibiting a higher tendency for impulsive behavior on this task showed a similar magnitude of DA response with no apparent impairments in cortical 5-HT function.

\section{Regression Analysis of DA and 5-HT Levels with Performance}

Figure 6 shows the strength of relationship between DA and 5-HT efflux in the prefrontal cortex and premature responding under basal and task-related conditions. Extracellular levels of 5-HT correlated positively and signifi-
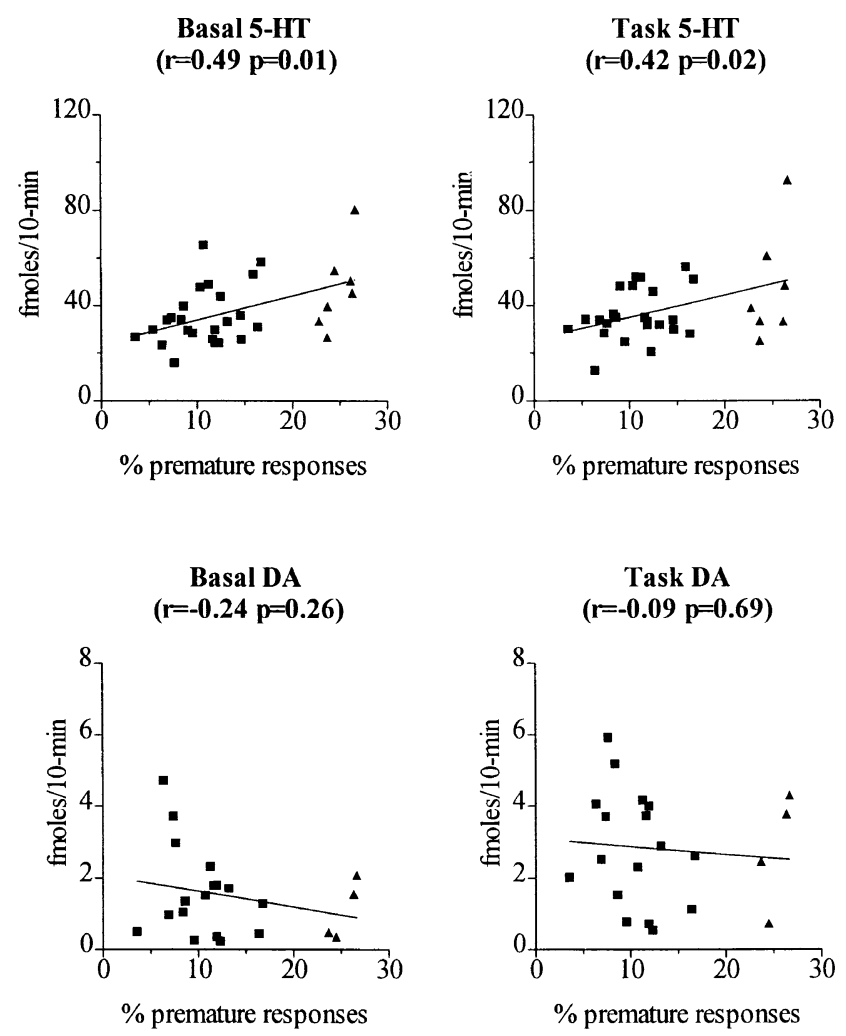

Figure 6. Positive correlation between in vivo 5-HT levels in the prefrontal cortex and impulsive behavior $(n=31)$. The relationship was linear both under basal conditions (average of three consecutive samples prior to task initiation) and during task performance (average of six consecutive samples). No significant correlations were found for levels of DA in the prefrontal cortex $(n=21)$. Squares and triangles represent low and high impulsive subjects, respectively. cantly with the percentage of premature responses both prior to $(\mathrm{r}=0.49 ; p=.01)$ and following $(\mathrm{r}=0.42 ; p=$ .02) task initiation. In contrast, there was no significant relationship between basal levels of DA and premature responses $(\mathrm{r}=-0.24 ; p=.26)$. Task-related levels of DA, though elevated compared with basal values, were also not related to premature responding. When highly impulsive subjects were removed from the analysis $(n=7)$ there remained a strong tendency for a positive relationship between 5-HT efflux and premature responding (basal: $\mathrm{r}=0.37 ; p=.071$, task: $\mathrm{r}=0.33 ; p=.12$ ). These data indicate that elevated 5-HT function in the prefrontal cortex may contribute to the expression of impulsive behavior on this task, despite the absence of differences between the low and high impulsive group.

\section{Post-mortem Assessment of 5-HT and DA Function}

Figure 1 shows representative coronal sections of the rat forebrain from which aliquots of tissue were extracted for the ex vivo analysis of 5-HT and DA function in low and high impulsive subjects. The concentrations of 5-HT and DA and their respective metabolites, 5-HIAA and DOPAC, measured from each brain region are shown in Table 1 and Table 2 . Listed also are utilization values for 5-HT and DA in each of the brain regions evaluated.

The most consistent differences between high and low response subjects were found with respect to DA function in the anterior cingulate, prelimbic and infralimbic cortices. This abnormality manifested as an increased utilization of DA in high response subjects, stemming mainly from an increased formation of DOPAC. This was particularly apparent in the anterior cingulate cortex where changes in DA function were symmetrical across hemisphere. Notably, no significant abnormalities in 5-HT function were observed in highly impulsive subjects in either the left or right cerebral cortex or striatum. In addition, irrespective of group, no significant correlations were found between premature responses and either individual levels of 5-HT or 5-HT utilization. However, DOPAC levels in both left $(\mathrm{r}=$ $0.43 ; p=.029)$ and right $(\mathrm{r}=0.40 ; p=.045)$ infralimbic cortex were found to correlate positively with impulsive anticipatory behavior.

\section{DISCUSSION}

This is the first investigation to evaluate the underlying neurochemical basis of a form of impulsivity using direct markers of brain 5-HT and DA function. The main finding was that increased 5-HT release, specifically in the prelimbic region of the prefrontal cortex, was associated with impulsive behavior on a task that places par- 
Table 1. Tissue concentrations and utilization of DA and 5-HT in the left cerebral cortex and striatum of low ( $\mathrm{n}=24$ ) and high $(\mathrm{n}=7)$ impulsive rats.

\begin{tabular}{|c|c|c|c|c|c|c|c|c|c|c|c|c|}
\hline \multirow{2}{*}{$\begin{array}{l}\text { Left } \\
\text { Brain region }\end{array}$} & \multicolumn{2}{|c|}{ 5-HT } & \multicolumn{2}{|c|}{ 5-HIAA } & \multicolumn{2}{|c|}{ DA } & \multicolumn{2}{|c|}{ DOPAC } & \multicolumn{2}{|c|}{ 5-HIAA/5-HT } & \multicolumn{2}{|c|}{ DOPAC/DA } \\
\hline & Low & High & Low & High & Low & High & Low & High & Low & High & Low & High \\
\hline IL & $\begin{array}{c}0.91 \\
(0.09)\end{array}$ & $\begin{array}{c}0.96 \\
(0.13)\end{array}$ & $\begin{array}{c}1.13 \\
(0.09)\end{array}$ & $\begin{array}{c}1.34 \\
(0.31)\end{array}$ & $\begin{array}{c}0.45 \\
(0.09)\end{array}$ & $\begin{array}{c}0.58 \\
(0.20)\end{array}$ & $\begin{array}{c}0.33 \\
(0.05)\end{array}$ & $\begin{array}{l}0.72^{+} \\
(0.21)\end{array}$ & $\begin{array}{c}1.38 \\
(0.13)\end{array}$ & $\begin{array}{c}1.38 \\
(0.24)\end{array}$ & $\begin{array}{c}0.98 \\
(0.14)\end{array}$ & $\begin{array}{c}1.33 \\
(0.19)\end{array}$ \\
\hline PL & $\begin{array}{c}0.64 \\
(0.05)\end{array}$ & $\begin{array}{c}0.71 \\
(0.10)\end{array}$ & $\begin{array}{c}0.94 \\
(0.06)\end{array}$ & $\begin{array}{c}1.01 \\
(0.21)\end{array}$ & $\begin{array}{c}0.32 \\
(0.05)\end{array}$ & $\begin{array}{c}0.23 \\
(0.05)\end{array}$ & $\begin{array}{c}0.16 \\
(0.03)\end{array}$ & $\begin{array}{c}0.35 \\
(0.19)\end{array}$ & $\begin{array}{c}1.49 \\
(0.09)\end{array}$ & $\begin{array}{c}1.45 \\
(0.18)\end{array}$ & $\begin{array}{c}0.57 \\
(0.10)\end{array}$ & $\begin{array}{l}1.23^{+} \\
(0.42)\end{array}$ \\
\hline $\mathrm{Cg}$ & $\begin{array}{c}0.60 \\
(0.03)\end{array}$ & $\begin{array}{c}0.72 \\
(0.17)\end{array}$ & $\begin{array}{c}0.84 \\
(0.07)\end{array}$ & $\begin{array}{c}0.88 \\
(0.10)\end{array}$ & $\begin{array}{c}0.21 \\
(0.02)\end{array}$ & $\begin{array}{c}0.21 \\
(0.03)\end{array}$ & $\begin{array}{c}0.11 \\
(0.01)\end{array}$ & $\begin{array}{l}0.26^{+} \\
(0.11)\end{array}$ & $\begin{array}{c}1.41 \\
(0.09)\end{array}$ & $\begin{array}{c}1.51 \\
(0.29)\end{array}$ & $\begin{array}{c}0.57 \\
(0.08)\end{array}$ & $\begin{array}{l}1.28^{+} \\
(0.56)\end{array}$ \\
\hline Fr2 & $\begin{array}{c}0.69 \\
(0.06)\end{array}$ & $\begin{array}{c}0.94 \\
(0.12)\end{array}$ & $\begin{array}{c}0.67 \\
(0.16)\end{array}$ & $\begin{array}{c}0.87 \\
(0.10)\end{array}$ & $\begin{array}{c}0.12 \\
(0.01)\end{array}$ & $\begin{array}{c}0.12 \\
(0.02)\end{array}$ & $\begin{array}{c}0.13 \\
(0.02)\end{array}$ & $\begin{array}{c}0.14 \\
(0.06)\end{array}$ & $\begin{array}{c}1.22 \\
(0.28)\end{array}$ & $\begin{array}{c}1.01 \\
(0.16)\end{array}$ & $\begin{array}{c}1.31 \\
(0.23)\end{array}$ & $\begin{array}{l}1.21 \\
(0.53)\end{array}$ \\
\hline $\operatorname{Pr}$ & $\begin{array}{c}0.74 \\
(0.04)\end{array}$ & $\begin{array}{c}0.72 \\
(0.09)\end{array}$ & $\begin{array}{c}0.53 \\
(0.07)\end{array}$ & $\begin{array}{c}0.52 \\
(0.05)\end{array}$ & $\begin{array}{c}0.15 \\
(0.02)\end{array}$ & $\begin{array}{c}0.12 \\
(0.02)\end{array}$ & $\begin{array}{c}0.07 \\
(0.03)\end{array}$ & $\begin{array}{c}0.05 \\
(0.02)\end{array}$ & $\begin{array}{c}0.76 \\
(0.08)\end{array}$ & $\begin{array}{c}0.82 \\
(0.19)\end{array}$ & $\begin{array}{c}0.40 \\
(0.13)\end{array}$ & $\begin{array}{l}0.36 \\
(0.11)\end{array}$ \\
\hline A & $\begin{array}{c}0.65 \\
(0.05)\end{array}$ & $\begin{array}{c}0.89 \\
(0.17)\end{array}$ & $\begin{array}{c}0.85 \\
(0.05)\end{array}$ & $\begin{array}{c}1.07 \\
(0.13)\end{array}$ & $\begin{array}{c}5.31 \\
(0.60)\end{array}$ & $\begin{array}{c}5.98 \\
(1.32)\end{array}$ & $\begin{array}{c}4.62 \\
(0.50)\end{array}$ & $\begin{array}{c}6.41 \\
(1.35)\end{array}$ & $\begin{array}{c}1.37 \\
(0.08)\end{array}$ & $\begin{array}{c}1.33 \\
(0.20)\end{array}$ & $\begin{array}{c}1.05 \\
(0.13)\end{array}$ & $\begin{array}{l}1.27 \\
(0.40)\end{array}$ \\
\hline VM & $\begin{array}{c}0.57 \\
(0.06)\end{array}$ & $\begin{array}{c}0.66 \\
(0.10)\end{array}$ & $\begin{array}{c}0.55 \\
(0.03)\end{array}$ & $\begin{array}{c}0.61 \\
(0.05)\end{array}$ & $\begin{array}{c}8.68 \\
(0.85)\end{array}$ & $\begin{array}{c}8.95 \\
(0.94)\end{array}$ & $\begin{array}{c}5.72 \\
(0.91)\end{array}$ & $\begin{array}{l}5.29 \\
(1.36)\end{array}$ & $\begin{array}{c}1.08 \\
(0.13)\end{array}$ & $\begin{array}{c}1.04 \\
(0.16)\end{array}$ & $\begin{array}{c}0.85 \\
(0.18)\end{array}$ & $\begin{array}{c}0.69 \\
(0.18)\end{array}$ \\
\hline $\mathrm{DM}$ & $\begin{array}{c}0.58 \\
(0.06)\end{array}$ & $\begin{array}{c}0.60 \\
(0.14)\end{array}$ & $\begin{array}{c}0.45 \\
(0.03)\end{array}$ & $\begin{array}{c}0.42 \\
(0.03)\end{array}$ & $\begin{array}{l}12.82 \\
(1.03)\end{array}$ & $\begin{array}{l}11.95 \\
(1.10)\end{array}$ & $\begin{array}{c}5.71 \\
(0.91)\end{array}$ & $\begin{array}{c}6.35 \\
(0.80)\end{array}$ & $\begin{array}{c}0.84 \\
(0.06)\end{array}$ & $\begin{array}{c}0.87 \\
(0.21)\end{array}$ & $\begin{array}{c}0.53 \\
(0.11)\end{array}$ & $\begin{array}{c}0.58 \\
(0.08)\end{array}$ \\
\hline DL & $\begin{array}{c}0.57 \\
(0.05)\end{array}$ & $\begin{array}{c}0.61 \\
(0.05)\end{array}$ & $\begin{array}{c}0.78 \\
(0.18)\end{array}$ & $\begin{array}{c}0.60 \\
(0.03)\end{array}$ & $\begin{array}{l}13.33 \\
(0.80)\end{array}$ & $\begin{array}{l}13.72 \\
(0.84)\end{array}$ & $\begin{array}{c}5.98 \\
(0.85)\end{array}$ & $\begin{array}{c}7.42 \\
(1.74)\end{array}$ & $\begin{array}{c}1.35 \\
(0.22)\end{array}$ & $\begin{array}{c}1.02 \\
(0.14)\end{array}$ & $\begin{array}{c}0.48 \\
(0.07)\end{array}$ & $\begin{array}{c}0.54 \\
(0.11)\end{array}$ \\
\hline $\mathrm{VL}$ & $\begin{array}{c}0.67 \\
(0.05)\end{array}$ & $\begin{array}{c}0.60 \\
(0.09)\end{array}$ & $\begin{array}{c}0.80 \\
(0.05)\end{array}$ & $\begin{array}{c}0.79 \\
(0.10)\end{array}$ & $\begin{array}{l}13.24 \\
(0.87)\end{array}$ & $\begin{array}{l}11.83 \\
(1.22)\end{array}$ & $\begin{array}{c}5.67 \\
(0.81)\end{array}$ & $\begin{array}{c}7.16 \\
(1.87)\end{array}$ & $\begin{array}{c}1.19 \\
(0.07)\end{array}$ & $\begin{array}{c}1.21 \\
(0.14)\end{array}$ & $\begin{array}{c}0.45 \\
(0.10)\end{array}$ & $\begin{array}{c}0.65 \\
(0.17)\end{array}$ \\
\hline $\mathrm{Cg}^{*}$ & $\begin{array}{c}0.53 \\
(0.06)\end{array}$ & $\begin{array}{c}0.54 \\
(0.11)\end{array}$ & $\begin{array}{c}0.74 \\
(0.08)\end{array}$ & $\begin{array}{c}0.70 \\
(0.12)\end{array}$ & $\begin{array}{c}0.26 \\
(0.02)\end{array}$ & $\begin{array}{c}0.24 \\
(0.05)\end{array}$ & $\begin{array}{c}0.24 \\
(0.04)\end{array}$ & $\begin{array}{c}0.30 \\
(0.06)\end{array}$ & $\begin{array}{c}1.46 \\
(0.14)\end{array}$ & $\begin{array}{c}1.83 \\
(0.68)\end{array}$ & $\begin{array}{c}1.04 \\
(0.19)\end{array}$ & $\begin{array}{c}1.28 \\
(0.24)\end{array}$ \\
\hline $\operatorname{Pr}^{*}$ & $\begin{array}{c}0.62 \\
(0.04)\end{array}$ & $\begin{array}{c}0.71 \\
(0.07)\end{array}$ & $\begin{array}{c}0.51 \\
(0.05)\end{array}$ & $\begin{array}{c}0.50 \\
(0.07)\end{array}$ & $\begin{array}{c}0.13 \\
(0.01)\end{array}$ & $\begin{array}{c}0.13 \\
(0.03)\end{array}$ & $\begin{array}{c}0.10 \\
(0.05)\end{array}$ & $\begin{array}{c}0.11 \\
(0.06)\end{array}$ & $\begin{array}{c}1.04 \\
(0.13)\end{array}$ & $\begin{array}{c}0.72 \\
(0.09)\end{array}$ & $\begin{array}{c}0.84 \\
(0.46)\end{array}$ & $\begin{array}{c}1.00 \\
(0.56)\end{array}$ \\
\hline
\end{tabular}

The data are averaged levels ( \pm S.E.M.) expressed as ng/mg. 5-HT and DA utilization indices were determined by the ratio of the respective metabolite to parent transmitter. Abbreviations are shown in Figure $1 .{ }^{+} p<.05$ (versus 'low' subjects).

ticular demands on response control. The positive relationship between elevated 5-HT release and loss of impulse control was evident despite time of sampling, either before or during task performance, suggesting that this may be a deficit linked to the tonic regulation of 5-HT release. Previous studies have strongly implicated serotonergic influences on impulsivity (Soubrié 1986, Stein et al. 1993; Harrison et al. 1997a; Puumala and Sirviö 1998; Evenden 1999b; Fairbanks et al. 2001), particularly when associated with aggression (Brown et al. 1982; Linnoila et al. 1983; Van Erp and Miczek 2000). Many of these reports have linked impulsive tendencies with a deficiency in 5-HT function. However, this conclusion has been based largely on relatively indirect measures of brain serotonergic function such as cerebrospinal fluid concentrations of 5-HIAA, platelet 5-HT activity and behavioral and neuroendocrine effects of relatively selective 5-HT agents. The results of the present study strongly question the nature of the 5-HT deficit in impulsivity, particularly its relationship to the control of responding in anticipation of reward. A second major finding of this investigation was the clear delineation of subjects into at least two distinct groups based on their impulsive tendencies. Subjects that were highly impulsive on the task showed a diffuse, but nevertheless highly specific, impairment in DA function in several regions of the prefrontal cortex, including the prelimbic, infralimbic and anterior cingulate cortices. The discussion that follows addresses the nature and specificity of the apparent 5-HT deficit in impulsivity.

A number of lesion and pharmacological studies have examined the relationship between brain 5-HT function and performance of rats on a 5-CSRT task (Harrison et al. 1997a; Puumala and Sirviö 1998; Carli and Samanin 2000; Koskinen et al. 2000a). The most consistent effect of these manipulations has been on premature responding, particularly after widespread 5-HT depletion with the selective neurotoxin, 5,7-dihydroxytryptamine (Harrison et al. 1997a). A similar pattern of responding has been observed following systemic administration of $5-\mathrm{HT}_{1 \mathrm{~A}}$ and $5-\mathrm{HT}_{2 \mathrm{a}}$ agonists (Carli and Samanin 2000; Koskinen et al. 2000a,b). Although these data strongly implicate 5-HT in aspects of response control on this task their precise relationship to dynamic 5HT transmission is less clear. For example, compensatory changes occurring as a result of the lesion, such as sprouting of damaged neurons and postsynaptic receptor supersensitivity (Bjorklund et al. 1973; Nelson et al. 1978; Gately et al. 1986) may have confounded the results, perhaps by enhancing 5-HT function overall. Indeed, recent in vivo microdialysis studies have shown that the release of other monoamine neurotransmitters such as DA and noradrenaline actually increase in terminal regions of the forebrain following partial lesions of 
Table 2. Tissue concentrations and utilization of DA and 5-HT in the right cerebral cortex and striatum of low $(\mathrm{n}=24)$ and high $(\mathrm{n}=7)$ impulsive rats.

\begin{tabular}{|c|c|c|c|c|c|c|c|c|c|c|c|c|}
\hline \multirow{2}{*}{$\begin{array}{l}\text { Right } \\
\text { Brain region }\end{array}$} & \multicolumn{2}{|c|}{ 5-HT } & \multicolumn{2}{|c|}{ 5-HIAA } & \multicolumn{2}{|c|}{ DA } & \multicolumn{2}{|c|}{ DOPAC } & \multicolumn{2}{|c|}{ 5-HIAA/5-HT } & \multicolumn{2}{|c|}{ DOPAC/DA } \\
\hline & Low & High & Low & High & Low & High & Low & High & Low & High & Low & High \\
\hline \multirow[t]{2}{*}{ IL } & 0.89 & 0.84 & 1.05 & 1.09 & 0.49 & 0.50 & 0.28 & $0.70^{+}$ & 1.37 & 2.24 & 0.77 & 1.28 \\
\hline & $(0.08)$ & $(0.17)$ & $(0.06)$ & $(0.11)$ & $(0.09)$ & $(0.14)$ & $(0.06)$ & $(0.21)$ & $(0.15)$ & $(1.02)$ & $(0.17)$ & $(0.47)$ \\
\hline \multirow[t]{2}{*}{ PL } & 0.66 & 0.73 & 0.98 & 0.93 & 0.31 & 0.32 & 0.28 & 0.30 & 1.47 & 1.42 & 1.04 & 0.99 \\
\hline & $(0.09)$ & $(0.12)$ & $(0.13)$ & $(0.12)$ & $(0.04)$ & $(0.09)$ & $(0.06)$ & $(0.14)$ & $(0.13)$ & $(0.26)$ & $(0.17)$ & $(0.37)$ \\
\hline \multirow[t]{2}{*}{$\mathrm{Cg}$} & 0.60 & 1.00 & 0.84 & 0.72 & 0.21 & 0.18 & 0.10 & $0.23^{+}$ & 1.41 & 1.15 & 0.57 & $1.37^{+}$ \\
\hline & $(0.03)$ & $(0.44)$ & $(0.07)$ & $(0.10)$ & $(0.02)$ & $(0.03)$ & $(0.01)$ & $(0.09)$ & $(0.09)$ & $(0.20)$ & $(0.09)$ & $(0.42)$ \\
\hline \multirow[t]{2}{*}{ Fr2 } & 0.83 & 0.80 & 0.65 & 0.56 & 0.16 & 0.11 & 0.30 & 0.24 & 1.10 & 0.72 & 0.66 & 0.42 \\
\hline & $(0.11)$ & $(0.09)$ & $(0.06)$ & $(0.12)$ & $(0.04)$ & $(0.02)$ & $(0.14)$ & $(0.02)$ & $(0.24)$ & $(0.16)$ & $(0.08)$ & $(0.15)$ \\
\hline \multirow[t]{2}{*}{$\operatorname{Pr}$} & 0.74 & 0.84 & 0.53 & 0.44 & 0.15 & 0.13 & 0.07 & 0.20 & 0.76 & 0.58 & 0.40 & 0.31 \\
\hline & $(0.04)$ & $(0.15)$ & $(0.07)$ & $(0.05)$ & $(0.02)$ & $(0.02)$ & $(0.03)$ & $(0.16)$ & $(0.08)$ & $(0.10)$ & $(0.13)$ & $(0.12)$ \\
\hline \multirow[t]{2}{*}{ A } & 0.68 & 0.65 & 0.83 & 0.86 & 5.42 & 4.30 & 4.05 & 5.24 & 1.29 & 1.48 & 1.24 & 1.32 \\
\hline & $(0.05)$ & $(0.09)$ & $(0.05)$ & $(0.10)$ & $(0.67)$ & $(0.42)$ & $(0.45)$ & $(0.84)$ & $(0.08)$ & $(0.30)$ & $(0.31)$ & $(0.29)$ \\
\hline \multirow[t]{2}{*}{ VMS } & 0.62 & 0.68 & 0.64 & 0.66 & 9.87 & 9.95 & 5.44 & 7.97 & 1.06 & 1.03 & 0.75 & 0.87 \\
\hline & $(0.04)$ & $(0.08)$ & $(0.04)$ & $(0.04)$ & (0.89) & $(0.96)$ & $(0.60)$ & $(1.42)$ & $(0.06)$ & $(0.16)$ & $(0.15)$ & $(0.19)$ \\
\hline \multirow[t]{2}{*}{ DMS } & 0.47 & 0.48 & 0.44 & 0.44 & 12.80 & 12.80 & 6.26 & 7.76 & 0.95 & 1.00 & 0.62 & 0.68 \\
\hline & $(0.02)$ & $(0.08)$ & $(0.03)$ & $(0.07)$ & $(0.95)$ & $(0.96)$ & (1.10) & $(2.15)$ & $(0.06)$ & $(0.16)$ & $(0.14)$ & $(0.15)$ \\
\hline \multirow[t]{2}{*}{ DLS } & 0.63 & 0.60 & 0.63 & 0.61 & 13.89 & 13.75 & 7.18 & 5.66 & 1.05 & 1.15 & 0.56 & 0.44 \\
\hline & $(0.06)$ & $(0.07)$ & $(0.04)$ & $(0.04)$ & $(0.73)$ & $(0.64)$ & (1.19) & $(0.72)$ & $(0.07)$ & $(0.26)$ & $(0.10)$ & $(0.08)$ \\
\hline \multirow[t]{2}{*}{ VLS } & 0.67 & 0.68 & 0.74 & 0.78 & 12.53 & 13.83 & 5.71 & 5.75 & 1.15 & 1.03 & 0.59 & 0.41 \\
\hline & $(0.04)$ & $(0.10)$ & $(0.04)$ & $(0.05)$ & $(0.89)$ & (1.06) & $(0.88)$ & $(1.01)$ & $(0.05)$ & $(0.10)$ & $(0.13)$ & $(0.05)$ \\
\hline \multirow[t]{2}{*}{$\mathrm{Cg}^{*}$} & 0.58 & 0.60 & 0.69 & 0.68 & 0.24 & 0.23 & 0.26 & 0.23 & 1.26 & 1.26 & 1.25 & 1.06 \\
\hline & $(0.05)$ & $(0.11)$ & $(0.06)$ & $(0.10)$ & $(0.02)$ & $(0.06)$ & $(0.07)$ & $(0.06)$ & $(0.09)$ & $(0.18)$ & $(0.35)$ & $(0.22)$ \\
\hline \multirow[t]{2}{*}{$\operatorname{Pr}^{*}$} & 0.63 & 0.68 & 0.47 & 0.44 & 0.12 & 0.11 & 0.10 & 0.11 & 0.80 & 0.72 & 0.57 & 1.10 \\
\hline & $(0.05)$ & $(0.09)$ & $(0.04)$ & $(0.03)$ & $(0.01)$ & $(0.02)$ & $(0.06)$ & $(0.04)$ & $(0.07)$ & $(0.10)$ & $(0.26)$ & $(0.39)$ \\
\hline
\end{tabular}

The data are averaged levels ( \pm S.E.M.) expressed as ng/mg. 5-HT and DA utilization indices were determined by the ratio of the respective metabolite to parent transmitter. Abbreviations are shown in Figure $1 .{ }^{+} p<.05$ (versus 'low' subjects).

the ascending catecholaminergic pathways (Parkinson et al. 2001; Hughes and Stanford 1998). Although this phenomenon has yet to be demonstrated for the ascending 5-HT systems, a recent study has shown that basal levels of extracellular 5-HT, albeit it in the striatum, are not altered by a near $75 \%$ depletion of tissue $5-\mathrm{HT}$ induced by intraventricular 5,7-dihydroxytryptamine (Hall et al. 1999). However, in the latter study two weeks only elapsed between surgery and testing, a recovery time that may have been insufficient to allow for functional compensation. Therefore, the assumption that depletion of 5-HT with 5,7-dihydroxytryptamine invariably leads to diminished 5-HT release requires more a rigorous analysis before more definitive conclusions can be drawn on the net effect of this lesion on 5-HT transmission.

Alternatively, it should be noted that while the present data reflect 5-HT function within a discrete region of anterior cortical circuitry, other lesion-based studies involve profound 5-HT depletion from widespread regions of the brain, both cortically and sub-cortically. Therefore, it is plausible that, as for the mesocortical and mesostriatal DA systems (Pycock et al. 1980), there exists a reciprocal balance in the functioning of cortical and subcortical 5-HT systems that can accommodate all of the main findings.

Impulsivity has also been inferred from other operant-based tasks such as a delay-of-reward procedure where subjects must choose between a small immediate reward and a larger but delayed reward. Disruption of 5-HT function by intra-raphé injections of 5,7-dihydroxytryptamine promotes impulsive choice for the smaller immediate reward (Wogar et al. 1993; Ho et al. 1998; Mobini et al. 2000). Similar effects of 5-HT depleting lesions on impulsivity have been inferred from other operant paradigms, including a conditional go/no-go visual discrimination task (Harrison et al. 1999) and reinforcement schedules with low response rates (Wogar et al. 1993). The findings of the present study challenge the view that these effects need necessarily be mediated by diminished 5-HT function. Further studies will be necessary to test the hypothesis that elevated 5-HT activity, as a consequence of compensation within the ascending 5-HT pathways, mediates impulsive tendencies in these behavioral settings.

The results of the present investigation have failed to replicate a recent finding that 5-HT utilization in the right frontal cortex significantly co-varies with premature responding on a 5-CSRT task (Puumala and Sirviö 1998). Several reasons may account for this apparent discrepancy including the different spatial arrangement of the task (one hole versus five holes) and procedural differences relating to the precise region of frontal cortex used for the chemical analyses. For example, Puumala and Sirviö (1998) found evidence for an inverse rela- 
tionship between 5-HT utilization in the right frontal cortex and choice accuracy, suggesting that 5-HT function in this region may interact with spatial discrimination and anticipatory responding. Nevertheless, both studies concur with the conclusion that absolute levels of 5-HT and its primary metabolite, 5-HIAA in the frontal cortex and striatum are not different in subjects with low and high impulsive tendencies. The dissociation between in vivo and ex vivo measures of 5-HT function in this study indicates that in vivo microdialysis is a particularly sensitive method for detecting abnormalities in cortical 5-HT function.

Further studies will be required to elucidate a possible causal relationship between elevated 5-HT release in the prefrontal cortex and impaired response control. However, a clue to the possible nature of this link is afforded by some recent preliminary findings that intracerebral infusions of the selective $5-\mathrm{HT}_{2 \mathrm{a}}$ receptor antagonist ketanserin directly into the medial prefrontal cortex reduce premature responding on the 5-CSRT task (Passetti F, Dalley JW, and Robbins TW, unpublished observations). Consistent with these data are recent findings that the 5- $\mathrm{HT}_{2 \mathrm{a} / 2 \mathrm{c}}$ receptor agonist, 2,5-dimethoxy-4iodophenyl-2-aminopropane (DOI), dose-dependently increases premature responding on the 5-CSRT, a response that is blocked by ketanserin (Koskinen et al. $2000 a, b)$. Interestingly, no significant effects of DOI were found after its direct administration into the anterior cingulate cortex (Koskinen et al. 2000b), an area which has been strongly implicated in impulsive responding on the 5-CSRT task (Muir et al. 1996). These data imply that DOI may exert its behavioral effects within other corticostriatal networks, including possibly the ventromedial prefrontal cortex and ventral striatum. Activation of 5$\mathrm{HT}_{2 \mathrm{a}}$ receptors is known to exert an excitatory influence on pyramidal neurons in layer $\mathrm{V}$ of the frontal cortex (Aghajanian and Marek 1997; Lambe et al. 2000), via increased release of glutamate from thalamocortical neurons (Scruggs et al. 2000). Pyramidal neurons in layer V are recognized to be an important source of output from the prefrontal cortex to subcortical structures, including the striatum, thalamus and brainstem (Gerfen 1989; Terreberry and Neafsey 1987; Deschenes et al. 1994; Levesque et al. 1996; Groenewegan et al. 1997). Therefore, over-activation of $5-\mathrm{HT}_{2 \mathrm{a}}$ receptors in layer $\mathrm{V}$ of the prefrontal cortex as a consequence of elevated 5-HT release (present study) may be an important mechanism that increases active responding in anticipation of reward. This hypothesis is currently being evaluated using highly selective $5-\mathrm{HT}_{2 \mathrm{a}}$ antagonists infused directly into both deep and superficial layers of the prefrontal cortex.

A further important finding of this study was that DA function, particularly in the anterior cingulate, prelimbic and infralimbic regions of the prefrontal cortex, was disrupted in subjects that were highly impulsive on the 5-CSRT task. It should be cautioned that only these differences in DA metabolism and utilization emerged from an analysis that encompassed over 10 brain areas and so may be subject to the problem of significant findings resulting from multiple statistical comparisons. However, both previous and currently presented evidence has strongly implicated these regions in the control of impulsive responding. Thus, dysfunction of probably homologous brain areas have also been observed in humans with attention deficit hyperactivity disorder (Ernst et al. 1998; Bush et al. 1999; Rubia et al. 1999), while in an animal model of this disorder ('the spontaneously hypertensive rat'), disturbances in DA release in the prefrontal cortex and striatum have been reported (Russell et al. 1995). It should be noted that while DA utilization in the prefrontal cortex was higher in subjects that were disproportionately impulsive on the task, no corresponding abnormality was detected in the regulation of DA release in this region. This apparent anomaly may be due to the fact that the dialysis probes sampled mainly from the prelimbic division of the prefrontal cortex, an area that was least disrupted in terms of DA turnover. Thus, our data indicate that frontal DA dysfunction may underlie certain forms of impulsive behavior although their relationship to the pathogenesis and treatment of ADHD are unknown.

In summary, the findings of this investigation are consistent with the notion that impulsive behavior probably arises from multiple abnormalities in the brain monoaminergic systems, possibly within frontostriatal circuitry. Clinically, these findings are relevant to impulsivity as seen in a variety of neuropsychiatric disorders, including $\mathrm{ADHD}$ and in depression in relation to suicide attempts (see Rahman et al. 2001). The challenge for further research will be to define more precisely the underlying neurobiology of different forms of impulsive behavior. Central to this aim will be a clearer understanding of how early life experiences and maturation processes during adolescence affect 5-HT and catecholamine function in later adult life (Robbins et al. 1996; Benes et al. 2000; Spear 2000).

\section{ACKNOWLEDGMENTS}

This work was supported by a Program grant from the Wellcome Trust. It was completed within a Medical Research Council Cooperative Group in Brain, Behavior and Neuropsychiatry. FP was supported by CeNeS plc, Cambridge, U.K.

\section{REFERENCES}

Aghajanian GK, Marek GJ (1997): Serotonin induces excitatory postsynaptic potentials in apical dendrites of neocortical pyramidal cells. Neuropharmacology 36:589-599

Ahn S, Phillips AG (1999): Dopaminergic correlates of sensory- 
specific satiety in the medial prefrontal cortex and nucleus accumbens of the rat. J Neurosci 19: RC29(1-6)

Barnes NM, Sharp T (1999): A review of central 5-HT receptors and their function. Neuropharmacology 38:1083-1152

Benes FM, Taylor JB, Cunningham MC (2000): Convergence and plasticity of monoaminergic systems in the medial prefrontal cortex during the postnatal period: implications for the development of psychopathology. Cereb Cortex 10:1014-1027

Björklund A, Nobin A, Stenevi U (1973): Regeneration of central serotonin neurons after axonal degeneration induced by 5,6-dihydroxytryptamine. Brain Res 50:214-220

Brown GL, Ebert MH, Goyer PF, Jimerson DC, Klein WJ, Bunney WE, Goodwin FK (1982): Aggression, suicide, and serotonin: relationship to CSF amine metabolites. Am J Psychiatry 139:741-746

Bush G, Frazier JA, Rauch SL, Seidman LJ, Whalen PJ, Jenike MA, Rosen BR, Biederman J (1999): Anterior cingulate cortex dysfunction in attention-deficit/hyperactivity disorder revealed by fMRI and the counting stroop. Biol Psychiatry 45:1542-1552

Carli M, Robbins TW, Evenden JL, Everitt BJ (1983): Effects of lesions to ascending noradrenergic neurons on performance of a 5-choice serial reaction time task in rats: implications for theories of dorsal noradrenergic bundle function based on selective attention and arousal. Behav Brain Res 9:361-380

Carli M, Samanin R (2000): The 5-HT(1A) receptor agonist 8-OH-DPAT reduces rats' accuracy of attentional performance and enhances impulsive responding in a fivechoice serial reaction time task: role of presynaptic 5-HT (1A) receptors. Psychopharmacology 149(3):259-268.

Dalley JW, Parker CA, Wulfert E, Hudson AL, Nutt DJ (1998): Potentiation of barbiturate-induced alterations in presynaptic noradrenergic function in rat frontal cortex by imidazol(in)e $\alpha 2$-adrenoceptor agonists. $\mathrm{Br} \mathrm{J}$ Pharmacol 125:441-446

Deschenes M, Bourassa J, Pinault D (1994): Corticothalamic projections from layer $\mathrm{V}$ cells in rats are collaterals of long range axons. Brain Res 664:215-219

Ernst M, Zametkin AJ, Matochik JA, Jons PH, Cohen RM (1998): DOPA decarboxylase activity in attention deficit hyperactivity disorder adults. A [fluorine-18]fluorodopa positron emission tomographic study. J Neurosci 18:5901-5907

Evans J, Platts H, Lightman S, Nutt D (2000): Impulsiveness and the prolactin response to d-fenfluramine. Psychopharmacology (Berl) 149:147-152

Evenden JL (1999a): The pharmacology of impulsive behavior in rats VII: the effects of serotonergic agonists and antagonists on responding under a discrimination task using unreliable visual stimuli. Psychopharmacology 146(4):422-431

Evenden JL (1999b): Impulsivity: a discussion of clinical and experimental findings. J Psychopharmacol 13:180-192

Fairbanks LA, Melega WP, Jorgensen MJ, Kaplan JR, McGuire MT (2001): Social impulsivity inversely associated with CSF 5-HIAA and fluoxetine exposure in vervet monkeys. Neuropsychopharmacology 24:370-378

Gately PF, Segal DS, Geyer MA (1986): The behavioral effects of depletions of brain serotonin induced by 5,7- dihydroxytryptamine vary with time after administration. Behav Neural Biol 45:31-42

Gerfen CR (1989): The neostriatal mosaic: striatal patchmatrix organization is related to cortical lamination. Science 246:385-388

Groenewegan HJ, Wright CI, Uylings HBM (1997): The anatomical relationships of the prefrontal cortex with limbic structures and the basal ganglia. J Psychopharmacol 11:99-106

Gronier B, Perry KW, Rasmussen K (2000): Activation of the mesocorticolimbic dopaminergic system by stimulation of muscarinic cholinergic receptors in the ventral tegmental area. Psychopharmacology (Berl) 147:347-355

Hall FS, Devries AC, Fong GW, Huang S, Pert A (1999): Effects of 5,7-dihydroxytryptamine depletion of tissue serotonin levels on extracellular serotonin in the striatum assessed with in vivo microdialysis: relationship to behavior. Synapse 33:16-25

Harrison AA, Everitt BJ, Robbins TW (1997a): Central 5-HT depletion enhances impulsive responding without affecting the accuracy of attentional performance: interactions with dopaminergic mechanisms. Psychopharmacology (Berl) 133:329-342

Harrison AA, Everitt BJ, Robbins TW (1997b): Doubly dissociable effects of median- and dorsal-raphé lesions on the performance of the five-choice serial reaction time test of attention in rats. Behav Brain Res 89:135-149

Harrison AA, Everitt BJ, Robbins TW (1999): Central serotonin depletion impairs both the acquisition and performance of a symmetrically reinforced go/no-go conditional visual discrimination. Behav Brain Res 100:99-112

Ho M-Y, Al-Zahrani SSA, Al-Ruwaitea ASA, Bradshaw CM, Szabadi E (1998): 5-hydroxytryptamine and impulse control: prospects for a behavioral analysis. J Psychopharmacol 12:68-78

Hughes ZA, Stanford SC (1998): A partial noradrenergic lesion induced by DSP-4 increases extracellular noradrenaline concentration in rat frontal cortex: a microdialysis study in vivo. Psychopharmacology (Berl) 136:299-303

Koskinen T, Ruotsalainen S, Puumala T, Lappalainen R, Koivisto E, Mannisto PT, Sirviö J (2000a): Activation of $5-\mathrm{HT}_{2 \mathrm{~A}}$ receptors impairs response control of rats in a five-choice serial reaction time task. Neuropharmacology 39:471-481

Koskinen T, Ruotsalainen S, Sirviö J (2000b): The 5- $\mathrm{HT}_{2}$ receptor activation enhances impulsive responding without increasing motor activity in rats. Pharmacol Biochem Behav 66:729-738

Lambe EK, Goldman-Rakic PS, Aghajanian GK (2000): Serotonin induces EPSCs preferentially in layer V pyramidal neurons of the frontal cortex in the rat. Cereb Cortex 10:974-980

Levesque M, Charara A, Gagnon S, Parent A, Deschenes M (1996): Corticostriatal projections from layer V cells are collaterals of long-range corticofugal axons. Brain Res 709:311-315

Linnoila M, Virkkunen M, Scheinin M, Nuutila A, Rimon R, Goodwin FK (1983): Low cerebrospinal fluid 5-hydroxyindoleacetic acid concentration differentiates impulsive from nonimpulsive violent behavior. Life Sci 33:2609-2614 
Matthews K, Dalley JW, Matthews C, Tsai T-H, Robbins TW (2001): Periodic maternal separation of neonatal rats produces regional and gender-specific effects on biogenic amine content in post-mortem adult brain. Synapse 40:1-10

Millan MJ, Dekeyne A, Gobert A (1998): Serotonin (5-HT) 2c receptors tonically inhibit dopamine (DA) and noradrenaline (NA), but not 5-HT, release in the frontal cortex in vivo. Neuropharmacology 37:953-955

Mobini S, Chiang T-J, Ho M-Y, Bradshaw CM, Szabadi E (2000): Effects of central 5-hydroxytrytamine depletion on sensitivity to delayed and probabilistic reinforcement. Psychopharmacology (Berl) 152:390-397

Morrow JD (1991): Psychostimulant medication: the pharmacotherapy of attention-deficit hyperactivity disorder. In Accardo PJ, Blondis TA, Whitman BY (eds), Attention Deficit Disorders and Hyperactivity in Children. New York, Marcel Dekker, Inc., pp 301-331

Muir JL, Everitt BJ, Robbins TW (1996): The cerebral cortex of the rat and visual attentional function: dissociable effects of mediofrontal, cingulate, anterior dorsolateral, and parietal cortex lesions on a five-choice serial reaction time task. Cereb Cortex 6:470-481

Nelson DL, Herbet A, Bourgoin S, Glowinski J, Hamon M (1978): Characteristics of central 5-HT receptors and their adaptive changes following intracerebral 5,7-dihydroxytryptamine administration in the rat. Mol Pharmacol 14:983-995

Palkovits M (1973): Isolated removal of hypothalamic or other brain nuclei of the rat. Brain Res 59:449-450

Parkinson JA, Dalley JW, Cardinal RN, Bamford A, Fehnert B, Lachenal G, Rudarakanchana N, Halkerston KM, Robbins TW, Everitt BJ (2001): Nucleus accumbens dopamine depletion impairs both acquisition and performance of appetitive Pavlovian approach behavior: implications for mesoaccumbens dopamine function. Behav Brain Res (in press)

Passetti F, Dalley JW, O'Connell MT, Everitt BJ, Robbins TW (2000): Increased acetylcholine release in the rat medial prefrontal cortex during performance of a visual attentional task. Eur J Neurosci 12:3051-3058

Paxinos G, Watson C (1986): The rat brain in stereotaxic coordinates. Sydney, Academic Press

Puumala T, Sirviö J (1998): Changes in activities of dopamine and serotonin systems in the frontal cortex underlie poor choice accuracy and impulsivity of rats in an attentional task. Neuroscience 83:489-499

Pycock CJ, Kerwin RW, Carter CJ (1980): Effect of lesion of cortical dopamine terminals on subcortical dopamine receptors in rats. Nature 286:74-77
Rahman S, Sahakian BJ, Cardinal RN, Rogers RD, Robbins TW (2001): Decision making and neuropsychiatry. Trends Cogn Sci 5:271-277

Robbins TW, Jones GH, Wilkinson LS (1996): Behavioral and neurochemical effects of early social deprivation in the rat. J Psychopharmacol 10:39-47

Rogers RD, Everitt BJ, Baldacchino A, Blackshaw AJ, Swainson R, Wynne K, Baker NB, Hunter J, Carthy T, Booker E, London M, Deakin JFW, Sahakian BJ, Robbins TW (1999): Dissociable deficits in the decision-making cognition of chronic amphetamine abusers, opiate abusers, patients with focal damage to the prefrontal cortex, and tryptophan-depleted normal volunteers: evidence for monoaminergic mechanisms. Neuropsychopharmacology 20:322-339

Rubia K, Overmeyer S, Taylor E, Brammer M, Williams SC, Simmons A, Bullmore ET (1999): Hypofrontality in attention deficit hyperactivity disorder during higherorder motor control: a study with functional MRI. Am J Psychiatry 156:891-896

Russell V, de Villiers A, Sagvolden T, lamm M, Taljaard J (1995): Altered dopaminergic function in the prefrontal cortex, nucleus accumbens and caudate-putamen of an animal model of attention-deficit hyperactivity disorder-the spontaneously hypertensive rat. Brain Res 676: 343-351

Scruggs JL, Patel S, Bubser M, Deutch AY (2000): DOIinduced activation of the cortex: dependence on $5-\mathrm{HT}_{2 \mathrm{~A}}$ heteroceptors on thalomocortical glutamatergic neurons. J Neurosci 20:8846-8852

Soubrié P (1986): Reconciling the role of central serotonin neurons in human and animal behavior. Behav Brain Res 9:319-364

Spear LP (2000): The adolescent brain and age-related behavioral manifestations. Neurosci Biobehav Rev 24:417-463

Stein DJ, Hollander E, Liebowitz MR (1993): Neurobiology of impulsivity and impulse control disorders. J Neuropsych Clin Neurosci 5:9-17

Terreberry RR, Neafsey EJ (1987): The rat medial prefrontal cortex projects directly to autonomic regions of the brainstem. Brain Res Bull 19:639-649

van Erp AMM, Miczek KA (2000): Aggressive behavior, increased accumbal dopamine, and decreased cortical serotonin in rats. J Neurosci 20:9320-9325

Wogar MA, Bradshaw CM, Szabadi E (1993): Effect of lesions of the ascending 5-hydroxytryptaminergic pathways on choice between delayed reinforcers. Psychopharmacology (Berl) 111:239-243 